\title{
Revista de la
}

\section{CEPAL}

Secretario Ejecutivo

Gert Rosenthal

Secretario Ejecutivo Adjunto

Andrés Bianchi

\section{Director de la Rerista}

Anibal Pinto

Secretario Técrico

Eugenio Lahera

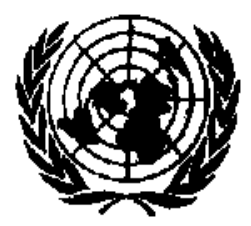

NACIONES UNIDAS

COMISION ECONOMICA PARA AMERICA LATINA Y EL CARIBE

SANTIAGO DE CHILE, DICIEMBRE 1988 


\section{Revista de la}

\section{CEPAL}

\section{SUMARIO}

Competitividad internacional: evolución y lecciones. F. Fajnzylber

Revolución industrial y alternativas regionales. H. Nochteff

Cambio técnico y reestructuración productiva. $E$. Lahera

Notas sobre la automatización microelectrónica en el Brasil. J.R. Tauile

Exportaciones e industrialización en la Argentina, 1973-1986. D. Azprazu y B. Kosacoff

Politica social rural en una estrategia de desarrollo sostenido. $J$. Durston

Interacción de los sectores público y privado y la eficiencia global de la economía. J.M.F. Martin

El problema de la deuda de Cuba en monedas convertibles. A.R.M. Ritter

La seguridad alimentaria; tendencias e impacto de la crisis. A. Schejtman

Economias de viabilidad difícil; una opción por examinar. A. Núñez del Prado

La génesis de la sustitución de importaciones en América Latina. R.L. Ground 
REVISTA DE LA CEPAL $\mathbf{N}^{\circ} 36$

\section{Política social}

rural en

\section{una estrategia de desarrollo sostenido}

\section{John Durston*}

En este articulo se examina la dinámica detectada en el último tiempo en los ámbitos social, demográfico y ocupacional del mundo rural, la que al sumarse a los problemas seculares del secior, presagia severos desequilibrios en el contex to de las nuevas modalidades de funcionamiento de las economías latinoamericanas que surjan de la actual crisis. Se plantea que en la mayoría de nuestros países la solución del problema del campesinado y el logro de un mayor grado de equidad en la sociedad rural, así cono entre ésta y la urbana, constituyen imperativos ineludibles para cualquier estrategia de desarrollo nacional que pretenda tenet viabilidad en los años noventa.

El autor esboza los rasgos esenciales de una estrategia de crecimiento con equidad rural y analiza algunas líneas alternativas de política social para el sector. Especial importancia atribuye a la materialización del potencial productivo de la economía campesina mediante el suministro adecuado de insumos, la introducción de reformas estructurales y la capacitación tanto de carácter técnico como para la participación en la toma de decisiones. Finalmente, subraya la importancia del papel del campesiuado en la expansión del mercado interno y en una estrategia viable de desarrotlo nacional.

* Puncionario de la División de Desarnollo Social de la CEPAL, Santiago de Chile.

\section{Introducción}

Los profundos trastornos económicos de los últimos años parecen haber cambiado radicalmente -quizás para siempre- la dinámica social que prevaleció por décadas en el medio rural. Ello exige modificar las reglas del juego que presiden el diseño de la política social para el sector.

En la mayoría de los países se percibe que el modelo de desarrollo seguido en la región antes de la crisis adolece de una insuficiencia esencial. Hasta fines de los años setenta parecía que continuaría indefinidamente el elevado ritmo de creación de nuevas ocupaciones productivas en actividades no agricolas, que habia hecho posible la movilidad social ascendente desde los estratos rurales pobres. Hoy en día, recuperar ese dinamismo parece difícil; $y$, en algunos países, poco menos que imposible (CEPAL, 1986 a),

Los procesos de transición económica, demográfica y cultural que se operaban en el mundo rural -con las modificaciones consiguientes en la articulación de éste con la sociedad y la economía urbanas- configuraban un eslabón clave de ese círculo supuestamente virtuoso del desarrollo previo a la crisis. Del mismo modo, una profunda redefinición del papel de la economia y la sociedad rurales en el desarrollo nacional parece constituir un elemento clave para la creación de estilos viables de desarrollo para la mayoría de los países latinoamericanos en las postrimerías del siglo $\mathrm{xx}$.

En un documento que resume el pensamiento diagnóstico y propositivo de la cepal se señala que la transformación de la estructura agraria es el punto de partida para el logro de "un umbral mínimo de equidad" en un contexto social que permita la modernización productiva y una genuina competitividad internacional (CEPAL, 1988 , p. 45 ).

En este artículo se postula que la incapacidad histórica para superar el problema de la pobreza y la inequidad rurales constituye un factor limitante de primer orden para el desarrollo de muchos países de la región. Por ende, cualquier estrategia alternativa que pretenda recuperar las tasas historicas de crecimiento debe encarar el desafio que plantea la pobreza rural. Tal imperativo resulta tanto más evidente si esa estrategia pretende aprovechar el potencial productivo no materializado de los estratos populares y las perspectivas que ofrece la ampliación del mercado interno. 
I

\section{El desafío de los próximos años}

En casi todos los países latinoamericanos los procesos de tecnificación, capitalización e integración de las economías rurales que se dieron antes de la crisis, transformaron y modernizaron las estructuras y mecanismos de extracción y exclusion de que habian sido objeto tradicionalmente los estratos campesinos (Durston, 1982). Sin embargo, ello no se tradujo en avances significativos en la distribución del ingreso y de los activos dentro de la población rural, ni entre esta última y la urbana.

Con la crisis económica de los años ochenta, "se vuelve dudosa la viabilidad de una dinámica que supuestamente habria de reducir la población activa en la agricultura mediante la capacitación y absorción en empleos productivos en otros sectores" (CEPAI., 1988, p. 56). Contra el resurgimiento de esta dinámica conspiran la persistencia de problemas de antigua data y la aparición de dificultades inéditas, asociadas a la coyuntura de la crisis y el ajuste, a lo que se agregan restricciones de largo alcance, vinculadas a las perspectivas de creación de empleos a futuro.

\section{Problemas seculares no resueltos}

El desarrollo agrícola basado en una capitalización que se concentra en el sector empresarial agravo el rezago de la población campesina, conformada por pequeños propietarios que explotaban minifundios crecientemente fragmentados, y de los obreros agrícolas sin tierra. La supervivencia de unos y otros dependía cada vez más de las oportunidades de trabajo asalariado estacional en la agricultura empresarial; y su progreso, del éxodo a la ciudad y del dinamismo de los mercados de trabajo urbanos. En este contexto estructural, el ritmo de crecimiento vegetativo de la población rural pobre, que aún hoy sigue siendo mucho más alto que el de la urbana, disminuía con lentitud.

El sesgo en la política agrícola a favor del sector de agricultura capitalista y el desamparo del campesinado frente a los mecanismos de extracción perpetuaban en la mayoría de los países el círculo vicioso de reproducción social de la pobreza en los medios rurales. En la medida que se negaba a los campesinos acceso a la tierra y a otras formas de capital, el único recurso productivo sobre el que ellos podían ejercer algún control continuaba siendo la fuerza de trabajo de sus hijos.

Por otra parte, ni el conjunto de pequeños predios familiares ni la agricultura capitalista fuertemente mecanizada pudieron absorber las cohortes cada vez más numerosas de jovenes que llegaban a la edad activa en el medio rural. Entre 1950 y 1980 la tasa media anual de crecimiento de la población ocupada en la agricultura no llegó ni siquiera al 1\% (cuadro 1). Además, este ritmo era decreciente, acercándose progresivamente a cero, y en algunos países la población agricola disminuyó en cifras absolutas.

Si la situación social rural no se tornó aún más crítica en el periodo 1950-1980 fue en parte

Cuadro 1

AMERICA LATINA: TASAS MEDIAS DE CRECIMIENTO ANUAL DE LA POBLACION OCUPADA EN LA AGRICULTURA Y DEL. PRODUCTO AGRICOLA

\begin{tabular}{lccccc}
\hline & $1950-1960$ & $1960-1970$ & $1970-1980$ & $1980-1987$ \\
\hline 1. Población ocupada en la agricultura & 0.8 & 0.7 & 0.3 & $1.7^{\mathrm{a}}$ \\
2. Producto agricola & 3.7 & 3.5 & 3.7 & 2.4 \\
\hline
\end{tabular}

Fnente: CEPAL, sobre la base de informaciones oficiales.

a Estimaciones preliminares de PREALC, sobre la base de informaciones oficiales de siete paises (Argentina, Brasil, Colombia, Costa Rica, Chile, México y Venezuela). 
porque efectivamente los empleos en sectores de mayor productividad -industria, comercio y servicios- aumentaron a tasas altas y crecientes, hasta superar el $5 \%$ anual promedio en los años setenta. Esto se tradujo en cierta movilidad social ascendente para gran parte de la fuerza de trabajo excedentaria en el medio rural.

La vigorosa creación de empleos en el sector urbano demandaba fuertes inversiones y un ritmo alto y estable de crecimiento del producto. En términos de promedios quinquenales, este último se mantuvo por encima del $5 \%$ anual a través de todo el período 1950-1980. Sin embargo, hacia fines de los años setenta ya muchos países habían completado la "fase fácil" del desarrollo, apreciándose claros síntomas de agotamiento de las fuentes que habían alimentado el mencionado proceso de transformación ocupacional.

En todo caso, entre 1950 y 1980 varias decenas de millones de personas de origen rural lograron insertarse en empleos no-agrícolas. Es cierto que gran parte de estos ex campesinos e hijos de campesinos continuaron sumidos en condiciones de explotacion y pobreza, en el sector formal de asalariados manuales o en el informal urbano. Sin embargo, es probable que en general sus protagonistas hayan percibido este cambio como un progreso, al cotejar su nueva realidad con la que habrían debido seguir soportando en el minifundio o en la condición de jornaleros agrícolas.

Al ser incapaz de liquidar las causas de la pobreza campesina, el modelo tradicional dependía de estos altos ritmos de creación de nuevos empleos en el sector no-agrícola moderno para ir absorbiendo una población rural pobre en vertiginoso aumento. La posterior pérdida de dinamismo productivo y el estallido de la crisis del empleo urbano bloquean esta movilidad, frustrando abruptamente las expectativas de las nuevas generaciones rurales. Cobra renovada urgencia así el imperativo de procurar, en el propio medio rural, la solución del conjunto de carencias de sus estratos populares.

\section{La agudización reciente del déficit social rural}

Con el colapso de los mercados laborales urbanos durante los primeros años de la crisis, el crecimiento vegetativo de la fuerza de trabajo rural y el flujo de retorno al campo de migrantes urba- nos cesantes debieron ser absorbidos por el sector ocupacional "residual" -el campesino- o por la agricultura empresarial. En varios países de la región el empleo agricola se expandió más rápidamente que el no agrícola en este período (PREAlc, 1986). En consecuencia, según datos de PREALc, la población ocupada en agricultura creció casi $13 \%$ en siete años (1980-1987), mientras que en los 10 años precedentes habla aumentado en menos de un $3 \%$.

Hacia mediados de los años ochenta, la agricultura de exportación y, en menor grado, la de alimentos de consumo nacional se expandian rá. pidamente, aunque este efecto positivo resultó algo amortiguado por el debilitamiento de la demanda, tanto doméstica como externa, y por el encarecimiento del crédito (CEPAL-FAO, 1987). El crecimiento de la oferta de mano de obra rural en la mayoría de los países provocó, empero, una baja del salario agrícola (PREALc, 1986) y del ingreso por activo en los minifundios (CEPAL, 1987 a, p. 16). El aumento del producto agrícola parece haber beneficiado principalmente a los empresarios, agudizándose así la inequidad imperante en el campo.

Por otra parte, la restricción del gasto fiscal se traduce en un deterioro de la oferta de servicios de salud, educación y vivienda, así como en una merma de las inversiones en infraestructura, fomento del desarrollo y otras modalidades de redistribución social del ingreso. Ello agrava el deficit que padece la mayoría de los habitantes de las áreas rurales. Este doble rezago del ingreso monetario y social de las mayorias rurales (y urbanas) acentúa la contracción de la demanda interna y se transforma en fuente de tensión que plantea exigencias adicionales al diseño de un proyecto nacional de desarrollo que concite un apoyo ampliamente mayoritario.

\section{Nuevos parámetras económicos y demográficos del cambio social rural}

Los pronósticos de los expertos coinciden en que en el mediano plazo las tasas de incremento de la demanda mundial de productos agricolas de exportación, de la generación de puestos de trabajo en el sector "moderno" no agrícola y, por último, de la oferta de capital y crédito para la agricultura serán muy inferiores a las históricas. En contraste, la tasa de crecimiento de la población ocupada en la agricultura está aumentando, lo que 
revierte una tendencia de décadas (cuadro 1). Ello anticipa para el corto plazo una merma en el ingreso por habitante rural $y$ una mayor concentración sectorial del ingreso a favor de los poseedores de activos. Como, de otra parte, es improbable que se produzca una caída acelerada en el crecimiento vegetativo de los estratos pobres en los medios rurales, también puede afirmarse que persistirá la presión sobre los servicios sociales, en especial de atención materno-infantil y de enseñanza básica.

La gravedad de la situación actual y del pronóstico para el mediano plazo varia según el estadio de la transición demográfica y ocupacional en que se encuentre cada país (cuadro 2). Este doble proceso, que casi siempre acompaña al desarrollo económico, involucra una etapa central en cuyo transcurso las sociedades predominantemente agrarias, que exhiben elevadas tasas de natalidad y de mortalidad, se transforman en sociedades urbano-industriales y de servicios, con tasas de natalidad y de mortalidad relativamente bajas y estables. La mayoría de los países latinoamericanos vivio aceleradamente esta etapa durante las tres décadas previas al estallido de la crisis (CEPAL, 1986 a).

Las implicancias de esta transición para el crecimiento actual de la mano de obra varían de manera considerable entre distintos tipos de paises. En los integrantes del Grupo 1 (cuadro 2), en donde la mortalidad y la natalidad se estabilizaron hace ya tiempo en niveles relativamente bajos, la presión sobre el mercado laboral aumenta hoy en día en forma moderada. Pero en aquéllos en los que el ritmo de crecimiento demográfico alcanzó su apogeo en la última década (Grupo i1), la población en edad de trabajar continúa todavía expandiéndose a una tasa vertigi-

Cuadro 2

CAMBIOS EN EL CRECIMIENTO DE LA POBLACION

EN EDAD ACTIVA:

\begin{tabular}{|c|c|c|c|}
\hline & & $\begin{array}{c}\text { Periodo de } \\
\text { crecimiento máximo } \\
\text { y tasa alcanzada }\end{array}$ & $\begin{array}{c}\text { Tasa (\%) } \\
\text { media anual } \\
1980-85\end{array}$ \\
\hline \multirow[t]{4}{*}{ I. } & $\begin{array}{l}\text { Patses de transiaion } \\
\text { demogrdfica atsanxada }\end{array}$ & & \\
\hline & Uruguay & pre-1950 (...) & 0.7 \\
\hline & Argentina & pre-1950 (..) & 1.2 \\
\hline & Chile & $1975-80(2.6)$ & 2.3 \\
\hline \multirow[t]{10}{*}{ II. } & $\begin{array}{l}\text { Países de transiction } \\
\text { reciente }\end{array}$ & & \\
\hline & Brasil & $1965-80(3.1)$ & 2.6 \\
\hline & Colombia & $1965-70(3.4)$ & 2.9 \\
\hline & Panamá & $1975-80(9.7)$ & 3.1 \\
\hline & Peru் & $1975-80(3.2)$ & 3.1 \\
\hline & Costa Rica & $1975.80(4.3)$ & 3.2 \\
\hline & República Dominicana & $1975-80(3.6)$ & 3.3 \\
\hline & Venezuela & $1970-75(4.4)$ & 3.4 \\
\hline & Ecuador & $1980-85(3.5)$ & 3.5 \\
\hline & México & $1980-85(3.6)$ & 3.6 \\
\hline \multirow[t]{7}{*}{ III. } & $\begin{array}{l}\text { Países de transición } \\
\text { incípiente }\end{array}$ & & \\
\hline & Honduras & $1980.85(4.0)$ & 4.0 \\
\hline & Paraguay & $1975-80(4.1)$ & 3.7 \\
\hline & Nicaragua & futuro $(\ldots)$ & 3.6 \\
\hline & Guatemala & futuro $(\ldots)$ & 2.8 \\
\hline & Bolivia & futuro $(\ldots)$ & 2.6 \\
\hline & Haití & futuro $(\ldots)$ & 2.2 \\
\hline
\end{tabular}

Fuente: CEPAL, Anuario estadistico, 1987.

a Población entre 15 y 64 ańos de edad. 
nosa (del orden del $3 \%$ anual), superior a la de la población total. Más aún, en varios de los países en que la transición demográfica es todavia incipiente (Grupo uI), ese ritmo continuará intensificándose por un buen tiempo. Esto se debe a que el ritmo de crecimiento de la población en edad de trabajar responde no sólo a los nacimientos en los años anteriores, sino también a variaciones en la tasa de mortalidad, la cual es todavía alta en los países de ese grupo, siendo probable que durante varios lustros siga descendiendo en forma sostenida. En consecuencia, según proyecciones del CELADE, en 1990 la población económicamente activa habrá aumentado $9 \%$ en Uruguay y $15 \%$ en Argentina, comparada con la de 1980. La PEA de los paises de transición reciente o incipiente experimentará, en cambio, aumentos de entre 30 y $45 \%$.

En la abrumadora mayoría de los países latinoamericanos el producto nacional bruto por habitante se contrajo en el período 1980-1987 (CEPAL, 1987 b). En los países de transición demográfica y ocupacional incipiente, la caída fue de $18 \%$ en promedio. Como el ritmo de crecimiento de su población en edad activa no sólo es alto, sino que en varios de estos países seguirá aumentando, se hace difícil, en ausencia de trasformaciones de fondo en el estilo de desarrollo impe- rante, imaginar un alivio en el déficit de empleos productivos.

La consecuencia más devastadora para millones de hogares campesinos será el entierro de las esperanzas de que sus hijos protagonicen una movilidad social ascendente. La permanencia obligada en la agricultura, como refugio de última instancia, representa para la mano de obra afectada una pérdida subjetiva, además de objetiva, ya que involucra el abandono de anhelos muy arraigados, a menos que se introduzcan reformas que mejoren sustancialmente los ingresos de las personas activas en la agricultura.

Estos nuevos parámetros plantean a numerosos países latinoamericanos un gran desafio en materia de reformulación de las políticas sociales y de empleo para los años noventa. Es imperioso incrementar fuertemente, sobre todo en el medio rural, la tasa de generación de empleos productivos, y mejorar las condiciones de vida y la oferta de servicios sociales, con el objeto de potenciar recursos humanos actualmente mal aprovechados. Sólo atacando en sus raíces los problemas y desequilibrios sociales que por tanto tiempo han afectado a la mayoría de los habitantes de las zonas rurales, desajustes que de otra manera tenderán a agudizarse en el futuro, surgirán estilos de desarrollo viables en el mediano y largo plazo.

\section{II}

\section{Esencia de una estrategia de equidad rural}

\section{Desarrollo rural y estrategia global}

Los problemas y los procesos sociales urbanos y rurales están estrechamente interconectados. Cualquier política de desarrollo rural tendrá entonces que enmarcarse en una estrategia global, que cuente con apoyo mayoritario, para el país en su conjunto. Ahora bien, en la mayoría de las naciones latinoamericanas la crisis social involucra dos carencias fundamentales: déficit de ocupaciones adecuadamente productivas, causa principal de la insuficiencia de ingresos para cubrir las necesidades básicas, y escasa participación de los estratos populares en un proyecto colectivo de desarrollo nacional. En los estratos populares rurales ambas carencias encuentran sus expresiones más agudas (CEPAL, 1985). Por eso, en las propuestas cepalinas para encarar la crisis ocupan un lugar privilegiado el fortalecimiento y la ampliación del mercado nacional y el logro de un amplio consenso político en favor de un proyecto nacional de desarrollo, centrado en el aumento de la capacidad productiva y de demanda de amplios sectores de la sociedad hasta ahora marginados (CEPAL, 1988, pp. 25, 28 y 41 ).

En cuanto a la crisis de creación de empleo productivo, el análisis de las tendencias sugiere que en la próxima década la mano de obra re- 
dundante será absorbida no sólo por los servicios de baja productividad, sino también en la agricultura, en su carácter de sector "residual" o "de refugio". Hay evidencia asimismo, aparte de la que fluye de la inflexión en las tasas de crecimiento del empleo agrícola en los años de la crisis, de que la migración desde el campo a tas ciudades es sensible a los cambios en la diferencia de salarios urbano/rurales. El éxodo se intensifica cuando la brecha aumenta, y disminuye cuando la diferencia es menor (Commander y Peek, 1983).

Las manifestaciones de la crisis de empleo productivo que se observan en las áreas rurales constituyen parte de un problema más amplio y apremiante. Es preciso, por ende, arbitrar medidas de emergencia, que apunten tanto a la creación masiva de ocupaciones temporales como a la prestación de servicios sociales -atención médi$\mathrm{ca}$, nutrición, enseñanza básica- que complementen los ingresos de las familias pobres.

Más allá de la coyuntura, la persistencia de un sector popular rural que alberga sobre un tercio de la PEA total, con niveles muy bajos de productividad, puede vislumbrarse como una gran oportunidad, ya que hace viable una fase inicial "fácil" de aumento de productividad en actividades que exhiben muy baja densidad de capital. En principio, es económicamente más eficiente - y más eficaz, en términos de la materialización de un proyecto nacional de desarrollo sociopolítico- èlevar la productividad de muchos trabajadores ya ocupados (o subocupados) en la agricultura campesina, que generar con el mismo capital unas pocas vacantes laborales en sectores de alta productividad, con altos costos en términos de capital y de años de capacitación por puesto de trabajo creado. Los campesinos disponen de activos en forma de conocimiento y experiencia, aun cuando carezcan de capital y tecnología adecuados.

Las alternativas de propuestas de políticas de desarrollo rural presentadas aquí parten de la convicción de que un aumento marginal de los ingresos de los sectores populares urbanos y, especialmente, de los asalariados agrícolas y campesinos expandiría la actualmente deprimida demanda de productos alimenticios, ya que la elasticidad-ingreso de la demanda de alimentos es mayor mientras más bajo sea el nivel del ingreso. Por lo demás, la redistribución del consume y de los activos a favor de los sectores populares rurales contribuiría a un proceso de desarrollo nacional más equilibrado y viable en el largo plazo. Los esfuerzos por aumentar la capacidad de exportar, en fin, deben ser acompañados por otros orientados a expandir la capacidad efectiva de demanda en el mercado interno, entre otros, de productos agropecuarios.

\section{2. ${ }_{3}$ Receta o menú?: diversidad y complejidad de las sociedades rurales}

Las propuestas de acción resumidas aquí configuran una sintesis de apreciaciones sobre la realidad rural latinoamericana, las cuales, si bien no concitan aceptación universal, se apoyan en múltiples evidencias empíricas. No pretenden ser una "receta de cocina" para planificadores, sino un simple "menú" de medidas de diverso tipo, de corto, mediano y largo plazo, seleccionadas y articuladas aquí a la luz de los escenarios más previsibles. Por otra parte, el tamaño relativo que dentro de cada país exhiba, por ejemplo, una pujante agricultura empresarial con asalariados permanentes, un estrato de medianos agricultores modernos, un sector de minifundistas pauperizados y semiproletarizados, o cualquier combinación de estos sectores, hará más o menos viables diferentes combinaciones de las políticas mencionadas.

Las sociedades rurales latinoamericanas son por lo menos tan complejas como las urbanas, pero mucho menos conocidas (Lacroix, 1985). Cabría anadir que son mucho más disímiles entre sí que las urbanas, tanto de un país a otro como cuando se consideran regiones subnacionales: Las categorías de grandes ganaderos; dueños de plantaciones de cultivos tropicales o templados, anuales o permanentes; farmers capitalizados; campesinos ("viables" o "de supervivencia"); arrendatarios y medieros grandes y pequeños; asignatarios de reforma agraria; comunidades indígenas; asalariados permanentes, jornaleros temporales locales, migrantes o de residencia urbana, etc., son sólo una parte del cuadro. Datos censales de los años ochenta revelan que una fracción alta y creciente de la PEA rural $-21 \%$ en Brasil, 24 en Honduras, 36 en Ecuador, 40 en Argentina y hasta un 43\% en Panamá-se inserta en actividades no agrícolas (CEPAL, 1986 a, cuadro 25). Las ocupaciones de carácter popular 
más comunes son obrero manual (especialmente artesano, carpintero, albañil y jornalero de construcción) comerciante de diversos tipos, empleado doméstico, cargador y conductor en transporte. Pero tambien hay un creciente estrato medio rural no agricultor, conformado por profesionales y semiprofesionales (agrónomos, maestros de escuela, etc.), comerciantes mayoristas o representantes de empresas de insumos agrícolas, funcionarios y empleados de entidades financieras y comerciales, etc.

Evidentemente, las políticas sociales rurales han de tomar en cuenta las necesidades especificas de por lo menos los grupos más numerosos y desfavorecidos. Esto se ve complicado por la acelerada transformación que han experimentado las relaciones productivas en el campo, asociada al ocaso de la hacienda tradicional, donde los grandes propietarios imponían vínculos de dominacion y paternalistas sobre peones y minifundistas de los alrededores, todo lo cual experimenta un vuelco con el reemplazo de trabajadores asalariados por temporales. Esta transformación involucra también el surgimiento de empresarios modernos de tamaño mediano, algunos de los cuales se hallan muy ligados al mundo urbano, quienes están integrando avanzadas tecnologias y prácticas crediticias y de manejo financiero a la gestión agrícola. Por otra parte, es preciso advertir que la "ocupación principal" declarada al encuestador censal dista de constituir la única que desempeñan los habitantes rurales. Un elevado porcentaje de estos hogares sigue estrategias multiocupacionales, manteniendo a nivel de familia extendida cierta identidad de "campesinado semiproletarizado". Así, por ejemplo, aun cuando los asalariados agrícolas esgriman demandas específicas, comparten la cultura campesina y sus redes de solidaridad de parentesco y comunidad, tendiendo a identificarse con sus intereses (Llambi, 1979). De hecho, parte importante de los migrantes a las ciudades no se desvinculan de la economía campesina, sino que destinan sus ahorros precisamente a la capitalización de sus predios (Durston y Crivelli, 1984). Por lo tanto, una mejoría en la dotación de recursos o en las condiciones de intercambio del campesinado beneficiará también a estos trabajadores o los inducirá a reintegrarse a la empresa familiar.

Estas son las razones que hacen aconsejable transformar la materialización del potencial pro- ductivo del campesinado, centrada en la familia rural popular y la comunidad local, en la pieza clave de una estrategia de empleo productivo rural. En los países de transición ocupacional reciente o incipiente el campesinado sigue representando el grueso de la PEA agrícola y mantiene estrechas relaciones de interdependencia económica con sectores de asalariados en la agricultura comercial y de trabajadores manuales noagrícolas. Las propuestas de política orientadas a estos dos últimos sectores serán, en consecuencia, analizadas en íntima relación con las estrategias de desarrollo de la economía campesina.

\section{Los servicios sociales en una politica social rural}

La reorientación de los servicios sociales en el campo debe procurar el doble objetivo de redistribuir tanto el consumo como los activos. En el corto plazo, a tales servicios les compete asumir la clásica función asistencial de amortiguar y compensar las carencias más graves y las inequidades más agudas en la distribución del ingreso monetario. Para el mediano plazo, en cambio, están llamados a "dar los primeros pasos en una estrategia... para aumentar el control de recursos productivos por parte de sectores populares" (CEPAL, 1988). Esto apunta a incrementar la dotación de capacidad productiva que representan el conocimiento y las destrezas, la nutrición, la salud, etc., de los sectores populares rurales en particular. Los desequilibrios existentes en la distribución espacial del gasto social tornan imperativa su reorientación en favor de los estratos rurales pobres, así como la transferencia de recursos desde los sectores urbanos en situación más ventajosa, hasta que se alcance "el umbral mínimo de equidad", condición necesaria para el logro de un desarrollo sostenido.

La educación es el servicio social que más se ha expandido en las zonas rurales durante las últimas décadas. En términos generales, la población campesina tiene algún acceso a la enseñanza básica formal, aunque a menudo ésta se encuentra limitada a tres o cuatro años. En cambio, la educación secundaria, clave para la movilidad ocupacional en la economía moderna, sigue siendo casi inaccesible para la mayoría de los jóvenes rurales. A pesar de los avances conseguidos, en la 
mayoría de los países persiste la enorme brecha que siempre ha existido entre el nivel educacional medio de los habitantes rurales y el de las zonas urbanas (CEPAL, 1986 a, p. 90). Aún más, a causa del frecuente sesgo antirrural que exhibe el gasto público, la enseñanza primaria es deficiente, lo que le resta utilidad práctica en cuanto instrumento para que los educandos lleguen a comprender la nueva tecnología agrícola o se capaciten para el desempeño en otros sectores o para la participación ciudadana. El hecho de que los campesinos jóvenes que vuelven al campo tras completar el ciclo de la educación media no encuentren en la agricultura campesina ninguna aplicación práctica para un "capital humano" adquirido con tanto sacrificio, envuelve una cruel ironía. Al negarles el acceso a la tecnología avanzada y al crédito, se les priva de las posibilidades de utilizar la educación como canal de movilidad ocupacional sin abandonar la agricultura. Parece evidente que se requiere introducir simultáneamente tecnología y educación. En vista del dilema señalado, posiblemente el vehículo más apropiado para ello sea la readecuación de la enseñanza secundaria a las exigencias de modernización del medio. Sus egresados podrían transformarse en eficientes promotores del avance tecnológico, ya que ellos mismos tienen intereses en el éxito de este proceso.

\section{Politicas para la materialización del potencial productivo campesino}

Diversas propuestas de desarrollo rural concuerdan en que la pequeña agricultura familiar campesina encierra un potencial de productividad ecológicamente sostenible, el cual ha permanecido hasta ahora sofocado por las estructuras y relaciones sociales existentes. En numerosos países el campesinado genera el grueso de la oferta de granos básicos que consumen los estratos populares. Experiencias puntuales indican que podría llegar a constituir la base productiva de políticas de seguridad alimentaria y de satisfacción de necesidades nutricionales de toda la población (CEPAL-FAO, 1985; Schejtman, 1987a; y Durston, 1983a).

Extensa es la gama de medidas a la que es posible recurrir si se quiere que la política económica rural brinde decisivo apoyo al empeño de aumentar la producción y la productividad de la tierra' en el campesinado. La selección que se haga en cada caso dependerá del conjunto de necesidades y de la prioridad que se les otorgue, $y$ de las posibilidades y limitaciones (del medio, de los actores y del gobierno). Si bien las necesidades pueden ser identificadas técnicamente, las posibilidades y limitaciones tienen más que ver con la competencia por recursos fiscales escasos. La participación popular se erige asi en elemento clave del éxito de la meta política de lograr equidad y erradicar la pobreza extrema en el campo.

Invariablemente, las propuestas de estrategias de desarrollo terminan con un breve reconocimiento de la importancia de la participación popular. En el caso del desarrollo social rural, los análisis de experiencias concretas llegan a una conclusión casi unánime. Y es que el grado de participación popular en el diseño, administración, realización y toma de decisiones en los proyectos cuyos beneficiarios son los campesinos,constituye el factor más determinante del éxito o el fracaso de estos esfuerzos por elevar el nivel de vida de los sectores rurales postergados (Lacroix, 1985; CEPAL-FAO, 1985; Durston, 1983a; Thiesenhusen, 1987; y Longhurst, 1987).

Para la mayoria de los planificadores nacionales e internacionales la sociedad rural es una especie de caja negra, una realidad desconocida por ellos en sus vidas personales, generalmente circunscritas a la sociedad urbana. Por ende, la contribución de los mismos beneficiarios al diseño y a la identificación de actividades, proyectos y programas puede ser esencial. En igual sentido, las especificidades locales en términos de recursos, sistemas ecológicos y necesidades, hacen imposible anticipar desde el ċentro del país cuáles serán los elementos cruciales para el éxito de las políticas en cualquier contexto local especifico. La participación popular en comunidades o microrregiones es esencial para la adaptación de

\footnotetext{
'Los integrantes de la familia campesina son al mismo tiempo "trabajadores", "dueños" y "empresarios". No les interesa, entonces, tener menos trabajadores con mayor productividad por persona, sino conseguir un incremento de la rentabilidad del predio familiar. Por eso, el acento debe colocarse en la introducción de tecnologias que eleven la producividad de la tierra y no en las que ahorran mano de obra. La capacitación, antes que la maquinaria, debiera ser el elemento clave para inducir el mejoramiento de la productividad de la mano de obra.
} 
programas de cobertura nacional a las realidades especificas de cada localidad.

Por otra parte, las instituciones informales, comunitarias y de parentesco, lo mismo que las redes de ayuda mutua subyacentes, constituyen un recurso valioso, en cuanto instancias de participación popular. Este puede ser aprovechado para incentivar la movilización y articulación de las familias campesinas en pos de un esfuerzo común.

El aprovechamiento del potencial de la cultura $y$ las instituciones rurales informales plantea, sin embargo, uno de los mayores desafíos a la aplicación de los principios de la participación popular. En términos generales, los especialistas han superado el añejo prejuicio de que la cultura campesina no sería más que un obstáculo al desarrollo (en circunstancias de que ella está, en realidad, readecuándose en forma permanente a un medio en transformación acelerada). Pero no es menos cierto, también, que esa cultura contiene algunos elementos disfuncionales a los objetivos contemplados aquí, como son los típicos faccionalismos y personalismos, que asumen la forma de conflictos clientelistas. No es fácil, en este contexto, fomentar el crecimiento de los mecanismos existentes de ayuda y coordinación solidaria. Sin embargo, numerosas experiencias a través de la región indican que la tarea es posible, dados un diagnóstico sociocultural correcto y una metodología cuidadosamente adaptada a la realidad inmediata.

La dispersión espacial de los habitantes rurales dificulta la puesta en vigencia de programas de desarrollo en este medio. El establecimiento de una instancia de coordinación de y por los beneficiarios a nivel supralocal puede contribuir decisivamente a ligar comunidades mediante la participación en un esfuerzo de interés común. El relativo aislamiento y la autonomía histórica de las microrregiones rurales que se hallan sumidas en una pobreza aguda han permitido la supervivencia de estructuras de poder propias, con formas de dominación, de explotación y caciquismo político que constituyen unas de las principales trabas a los programas de desarrollo rural. El fomento de la participación popular tanto en la toma de decisiones como en el manejo de los programas son condiciones insoslayables si se quiere evitar el bloqueo de las iniciativas o la filtración de fondos hacia fines que poco tienen que ver con el desarrollo campesino.

La participación popular constituye, asimismo, parte de la solución del problema que surge de la inercia de las burocracias institucionalizadas sea en los servicios sociales o en los ministerios del área productiva. Como éstas tienden a defender sus estructuras y modus operandi, los programas nacionales nuevos que se diseñan especialmente para promover un desarrollo rural innovativo, suelen tener mayores probabilidades de éxito si logran combinar la participación popular con una dependencia directa sólo de la máxima instancia de poder político; un control independiente sobre un fondo de gastos fijos, salarios e inversión; $y$ facultades supervisoras sobre los organismos gubernamentales que es preciso reorientar (Lacroix, 1985).

La organización de la fuerza participativa y de presión de los sectores populares rurales es indispensable para viabilizar las propuestas de reforma estructural, sobre todo porque los campesinos suelen ser los "socios débiles" de cualquier concertación aglutinadora alrededor de un proyecto nacional. Si la estrategia global debe descansar significativamente en la creación de una "capacidad de acción colectiva organizada" (CEPAL, 1988), superar la laguna que existe hoy en día en este campo ha de constituir un desafío prioritario.

Una urgencia semejante tiene la meta de liquidar la falsa percepción de que el progreso rural está en pugna con el bienestar popular urbano. Sólo si la participación permite al campesinado aumentar su capacidad de negociación y de proyectar sus propias propuestas y alianzas, la sociedad podrá descubrir que la equidad en el medio rural es funcional al desarrollo productivo del país en su conjunto. En la mayoría de los países la población rural es minoritaria y en ninguno posee la fuerza suficiente para imponer sus reivindicaciones, de manera que carece de realismo propiciar una simple reasignación del consumo a favor de la población rural. Más bien, los recursos que se destinen a este sector han de considerarse una inversión, de la cual se beneficiará el conjunto del país, ya que, previsiblemente, ella permitirá expandir la capacidad productiva de los grupos más desprovistos de capital e incrementar la demanda de los bienes y servicios generados por otros sectores. 
Existe ya una nutrida literatura y una amplia práctica experimental en lo tocante a tecnologías capaces de aumentar la productividad de la empresa familiar campesina. Una de ellas ta constituye el conocimiento de variedades de cultivo, microclimas locales y prácticas que forman parte de la cultura campesina tradicional (Durston, 1983b). Es importante, en este contexto, desembarazarse del todo de la mencionada concepción de que esa cultura constituirfa un obstáculo para el cambio. "La tradición no es estática; se crea diariamente, se reconstruye cada hora, y se negocia socialmente dentro del hogar y entre el hogar y la comunidad a la cual éste pertenece" (Wilk, 1987).

Otro conjunto corresponde a las "tecnologías apropiadas", creadas muchas veces por la ciencia agricola moderna, pero con énfasis en los bajos costos y en el uso de insumos locales para la fabricación de maquinaria sencilla, la solución de dificultades de cultivo (falta de agua, tierras pobres y de ladera), y viabilidad ecológica a largo plazo (Altieri, 1987). Una tercera categoría tecnológica procampesina está representada por la aplicación de técnicas y descubrimientos en la frontera misma de la biotecnología, con énfasis en la creación de líneas de investigación que responden a necesidades de los pequeños productores (Wulf, 1986; Schejtman, 1987b).

Todas estas vertientes tienen una validez ampliamente comprobada en la práctica o en el análisis cientifico. La cuestión no reside, entonces, en si la tecnología puede o no aumentar en forma apreciable la productividad de la agricultura campesina, sino, como siempre, en si existe o no la capacidad política para canalizar los recursos suficientes para este propósito. Si ella existe, será preciso operacionalizar el corpus de tecnología apropiada, diseñando metodologías para integrarlo con las prácticas campesinas de cada medio local, entrenando cuadros y montando sistemas institucionales para llevarlo a la práctica.

Otro promisorio campo de acción es el del apoyo estatal al abastecimiento de insumos productivos y bienes de consumo básicos para los campesinos. En las experiencias que han logrado éxito en este terreno, el Estado o un organismo no gubernamental apoya la creación de cooperativas u organizaciones comunitarias campesinas y provee el financiamiento inicial recuperable para fondos rotatorios de crédito. Esta estrategia apunta a superar las limitaciones imperantes en el acceso a insumos a precios adecuados, las cuales obedecen a la ausencia de canales institucionales, de economías de escala y de conocimientos contables y administrativos (Barril, 1987).

Dado que los problemas y carencias del campesinado son multifacéticos, se requiere adicionalmente la aplicación de un enfoque que integre y coordine los diversos esfuerzos específicos. Los programas de desarrollo rural integral (DRI) se multiplicaron en la región durante la década de 1970. Su auge obedeció en gran medida al impulso dado a este tipo de enfoque por el Banco Mundial. A partir del escaso éxito de los programas tradicionales de fomento de la producción agropecuaria, se tomó conciencia de que la asistencia técnica productiva no es suficiente por sí sola para promover el desarrollo rural; menos, todavia, para avanzar hacia la equidad y conseguir la erradicación de la pobreza. Se descubrió, entonces, que el logro de estos objetivos exige la adopción de medidas especiales de tipo social, en combinación con proyectos de infraestructura y de producción, coordinadas a nivel regional de modo de configurar un todo orgánico y coherente.

Ahora bien, el escaso éxito que muestran también los programas DRI lleva en el último tiempo a una profunda reevaluación de este enfoque. De hecho, desde el estallido de la crisis de la década en curso el Banco Mundial no ha iniciado ningún nuevo programa DRI de gran envergadura. Se aduce que su alto costo y lo extenso de su cobertura hace que estos programas resulten inapropiados en una coyuntura de estrechez financiera y fiscal. Sin embargo, los principios esenciales del enfoque integral, entre los que destaca la complementariedad de las políticas económicas y sociales con el objeto de romper el círculo vicioso de reproducción de la pobreza, mantienen validez. El modelo fundamental del DR1 puede ser viable incluso en situaciones de escasez de recursos de capital, si en su reemplazo parcial se logra la adecuada incorporación de la fuerza de trabajo calificada que en la actualidad se encuentra subutilizada y si se consigue una auténtica participación popular.

Los proyectos DRI han tenido mayor éxito entre campesinos que son económicamente "viables", dado que ellos poseían desde antes suficiente tierra productiva y operaban en un medio que les aseguraba un mínimo de autonomía 
económica. Sin embargo, una fracción elevada del campesinado no goza de estas dos ventajas; en consecuencia, a veces sucede que los beneficiarios de proyectos DRI se convierten en dominadores de los campesinos más débiles, incrementándose asi la desigualdad rural (Dunham, 1983).

\section{Politica social en contextos de agricultura empresarial comercial}

Muchos proyectos de promoción de la empresa familiar campesina parecen haber sido diseñados como si ésta fuese autonoma de las estructuras de poder rural. En la mayoría de los casos, empero, el campesino se halla expuesto a una combinación de mecanismos y estrategias de las elites regionales. En las zonas de mayor modernización productiva, se han modernizado también los mecanismos sociales de extracción tradicionales, lo que se ha traducido en alteraciones en los términos de intercambio que enfrenta el estrato campesino productor de granos básicos, en un mayor endeudamiento, en contratos desventajosos con la agroindustria y en trabajo asalariado mal remunerado (Durston, 1982). Especialmente funcional para los agricultores comerciales resulta el limitado acceso a la tierra que tienen los campesinos "sin potencial de autosustentación alimentaria" (Schejtman, 1987b), ya que ello constituye una fuente de fuerza de trabajo asalariada ocasional, disponible a bajo costo cuando se la necesita. El minifundio absorbe parte del costo de reproducción de la fuerza de trabajo (vivienda y un porcentaje de la alimentación), con el aho. rro consiguiente para el empleador. Para remover este tipo de obstáculo, es evidente que se necesita algo más que el simple apoyo a la agricultura campesina.

En principio, la complementariedad cíclica laboral entre campesinado y sector empresarial puede ser modificada y reglamentada de manera que contribuya al avance hacia la equidad y a la erradicación de la pobreza rural. Para tal efecto, es necesario, en primer lugar, que el Estado in. troduzca cambios en las estructuras de relaciones económicas para liquidar los mecanismos de exclusión y extracción, de modo que la agricultura campesina familiar (individualmente o agrupada en organizaciones colectivas) pueda materializar su potencial. Segundo, si se establecen regulaciones a la agricultura empresarial y se promueve la sindicalización rural, puede asegurarse la vigencia de relaciones laborales más justas y estables.

Tres tipos de medidas parecen fundamentales para el logro de estos objetivos destinados a elevar la capacidad de producción y de demanda de los semiproletarios agrícolas y de los agricultores campesinos propiamente tales. El primer tipo de medidas apunta al mejoramiento del salario o jornal agrícola en el sector empresarial, cuyo monto suele ser muy inferior al que perciben los trabajadores urbanos (por ejemplo, en la construcción). La diferencia obedece en cierta medida a que parte del costo de reproducción de la fuerza de trabajo rural es absorbida por el sector minifundista; a que la mayor parte del tiempo hay mano de obra redundante; y a que los asalariados disponen de escaso poder de negociación para exigir mejores remuneraciones, máxime cuando en la actualidad los empleadores mues tran clara preferencia por los contratos temporales. Todas estas causas son a su vez resultados de las estructuras económicas y de poder vigentes en muchas zonas rurales.

La movilización sindical de jornaleros, en particular, requiere el apoyo (o por lo menos la protección) del Estado para que cristalice en una negociación colectiva justa en materias salariales. Por esta vía parece bastante factible conseguir un incremento de las remuneraciones en las actividades más dinámicas de la agricultura de cultivos industriales o de exportación, cuyos márgenes de ganancia suelen ser más amplios y en las que la mano de obra tiene escasa incidencia en el costo final del producto. Las mismas consideraciones parecen válidas para las actividades de procesamiento y embalaje; en todos estos casos, la participación popular reviste una importancia tan crucial (aunque en diferentes formas) como en el campesinado.

El segundo tipo de medidas se propone moderar los efectos del carácter fuertemente cíclico de la demanda de mano de obra por parte de la agricultura empresarial. Este se ha agudizado con la modernización de las grandes explotaciones, las cuales han reducido sustancialmente la planta de trabajadores permanentes y aumentado sus requerimientos estacionales para la cosecha y plantación. En el síndrome de pobreza del campesinado semiproletario, al bajo salario se añade la insuficiencia de su propia producción 
durante los largos periodos en que no hay trabajo en la gran explotación moderna.

Esta situación podría mejorar si se estabilizara la demanda de mano de obra agrícola a lo largo del ciclo anual: por ejemplo, dando preferencia, en el otorgamiento del crédito, a cultivos que requieren atención más constante o a los empresarios que adopten técnicas de uso más intensivo de mano de obra. Tambien las propuestas tendientes a aumentar la productividad predial campesina ayudarán al semiproletariado a mantenerse por encima de la pobreza cíclica en los meses en que no hay demanda de trabajo asalariado. A su turno, la absorción de mano de obra en el trabajo predial campesino reducirá la sobreoferta de jornaleros, lo cual podría forzar un aumento de sueldos, $y$, en última instancia, un incremento de la eficiencia genuina en el sector empresarial, en contraste con la "eficiencia espúrea", basada en el empobrecimiento de la mano de obra.

En la medida en que el ciclo de cultivo campesino coincide con el de la agricultura empresarial, tal aumento del empleo contribuiría, sin duda, a elevar el nivel de vida del semiproletario rural, pero tal vez dificulte la operación empresarial en sus momentos de máxima demanda. Se requiere arbitrar, entonces, medidas que generen una mayor complementariedad entre los ciclos anuales de tareas en la economía campesina, por un lado, y la demanda de mano de obra temporal en la agricultura empresarial, por el otro. En cada contexto microrregional existe una gama de alternativas de cultivos con diferentes ciclos anuales, cuya elección y fomento por el Estado deberán quedar supeditados en parte al aporte que hagan a la complementariedad en el uso de la fuerza de trabajo.

No se trata de crear condiciones que tornen insostenible la agricultura empresarial comercial eficiente. Esta ha tenido y debe seguir desempeñando un papel determinante en el aumento del producto agrícula. Es preciso, sin embargo, eliminar el sesgo que la favorece en muchos países y que impregna las políticas laborales, de precios y subsidios; la tributación, el gasto en infraestructura, las actividades de investigación y extensión, el otorgamiento de crédito, etc. Tal trato preferencial entraña una discriminación inaceptable en contra del campesinado y del proletariado agrícola. En efecto, en algunos casos una fracción de los recursos utilizados para financiar estas subvenciones directas e indirectas a la agricultura empresarial habría sido suficiente para impulsar la agricultura campesina (Hewitt, 1976; Estévez, 1980; Palau, 1987). Por otro lado, es imprescindible arbitrar reformas tributarias que graven las ganancias netas generadas por la agricultura empresarial, en lugar de seguir exigiendo el tradicional aporte al seguro social por número de personas empleadas, que desincentiva la contratación de mano de obra. La aplicación rigurosa de las normas tributarias vigentes bastaría para incrementar en forma apreciable la recaudación fiscal. Los fondos adicionales podrían destinarse a fomentar la elevación de la productividad y expandir la capacidad de demanda de los estratos rurales de menores ingresos.

\section{Reforma agraria, politica predial y desarrollo social}

El ejemplo más radical entre las políticas destinadas a corregir distorsiones en la relación entre la agricultura empresarial y la campesina consiste en la expropiación y transferencia de la propiedad de la tierra. Su aplicación tiene lugar en situaciones caracterizadas ya sea por un uso ineficiente de grandes extensiones de suelos productivos o de extrema concentración de la tierra y del agua, con severo perjuicio del bien común social.

En los últimos años, el tema de la reforma agraria parece estar recobrando vigencia, después de que durante una década fue prácticamente tabú en muchos países. Algunos estudios e informes recientes de organismos internacionales (Banco Interamericano de Desarrollo, 1986; Lacroix, 1985; Longhurst, 1987) consideran que en determinadas circunstancias es una medida legitima e incluso necesaria. "La reforma agraria... es una cuestión importante en varios países. Esto es lo que debe ocurrir cuando hay grandes desigualdades en la distribución del ingreso y de la tierra, cuando grandes superficies de tierra cultivable se someten a uso extensivo, y cuando las perspectivas de empleo en otros sectores económicos no son favorables" (BID, 1986, p. 155).

En realidad, el tema nunca fue considerado obsoleto por los expertos en desarrollo rural. Pero el modelo de modernización productiva y las teorías ortodoxas y neoliberales tan en boga en los años setenta y principios de la década en curso chocaban con este concepto de interven- 
ción estatal. Sea como fuere, la sucesión de reformas agrarias incompletas, simbólicas o revertidas en diversos países de la región dejaron intacto el problema de fondo, vale decir, la extrema concentración del capital fijo y financiero, del conocimiento, la tecnología y la infraestructura y de las redes de comercialización.

Los efectos negativos de la concentración de la tierra se hacen sentir no sólo en situaciones en que persisten modalidades tradicionales, aunque en alguna medida readecuadas, de producción agropecuaria, como la hacienda tradicional. Es cierto que en las zonas en que ha surgido una agricultura moderna, capitalizada y altamente competitiva, el tema de la reforma agraria se vuelve más conflictivo y difícil de justificar como medida de apropiación y distribución (Lacroix, 1985). Sin embargo, la dicotomía simple entre agricultura de hacienda y agricultura moderna ignora el hecho histórico de la alianza en diversas coyunturas entre sectores tradicionales hacendatarios y grupos empresarios modernos. Más todavía, parte importante de la modernización agricola ha tenido lugar precisamente en aquellas haciendas que fueron consideradas de carácter precapitalista, pero que en el hecho fueron modernizadas por sus dueños.

Asimismo, la imagen de eficientes y altamente productivos que se esfuerzan por proyectar muchos grandes agricultores distorsiona una realidad compleja, en la que a menudo el empleo de influencias políticas se tradujo en la obtención más o menos encubierta de cuantiosos subsidios y privilegios estatales. En medida variable según el país y la época, los precios fijados y los créditos subvencionados, aparte de otras formas indirectas de subvención - como la investigación agropecuaria estatal en cultivos comerciales-significan que los niveles de productividad del sector moderno son en la práctica inferiores a lo infor. mado, ya que esconden costos que han debido ser asumidos por la sociedad nacional en su conjunto.

Habitualmente la reforma agraria no es considerada entre las "políticas sociales". Sin embargo, se trata, obviamente, de la política redistributiva por excelencia. Constituye, asimismo, un instrumento potencialmente muy eficaz para conseguir la equidad, erradicar la extrema pobreza rural y aliviar las presiones migratorias sobre los mercados de trabajo y los servicios sociales urba- nos. En aquellos países en los que la extrema concentración de la tierra se da junto con la existencia de una población minifundista pauperizada y un campesinado semiproletario sin tierra, y en donde estas dos categorías conforman un porcentaje significativo de la población nacional, ta reforma de la estructura de tenencia de la tierra -incluido el suministro de apoyo técnico y crediticio para el incremento de la productividad de los beneficiarios- surge como una medida ineludible a mediano plazo.

A fin de cuentas, más allá de si en un país determinado debe o no aplicarse la reforma agraria en términos de un proceso de expropiación y redistribución de la tierra, parece apropiado sugerir que todo Estado defina una política permanente de tenencia y uso predial. Esta ha de estipular metas explícitas en cuanto a combinaciones óptimas de la configuración nacional de predios por tamaño, en relación con diferentes tipos de uso. Tales metas serían fruto de un esfuerzo deliberado por conciliar objetivos economicos y sociales, tomando en cuenta la relación entre posibles reformas prediales y el suministro de diversos insumos a la agricultura campesina, por un lado, y la aplicación de políticas salariales en el sector de agricultura empresarial, por otro.

Esta política de tenencia y uso predial, llamada a insertarse en un proyecto nacional global de desarrollo sostenido y equitativo, sería objeto de periódicas revisiones, con el fin de adecuarla a la evolución de las condiciones económicas y sociales y a eventuales cambios en las metas mismas, como consecuencia de modificaciones en la correlación de fuerzas políticas. Su principal ventaja seria proporcionar una visión global más coherente del complejo problema de la tenencia, facilitando, entre otras decisiones, la de si en una coyuntura determinada conviene o no aplicar una reforma agraria ${ }^{2}$.

\section{La creación de empleo mural no agricola}

Sea cual fuere el horizonte de tiempo que se adopte, es claro que la creación de nuevos empleos productivos fuera de la agricultura constituye

\footnotetext{
${ }^{2}$ Para profundizar en el debate reciente sobre la reforma agraria, véase, por ejemplo, Warman (1977), revista Coyurtuva agropecuaria (1987) y Ministerio de Desarrollo Agropecurio y Reforma Agraria de la República de Nicaragua (1986).
} 
pieza clave de cualquier estrategia de desarrollo rural con equidad. A corto plazo, representa una alternativa para encarar la emergencia provocada por la crisis, toda vez que el deterioro del ingreso de los trabajadores puede atenuarse mediante el empleo creado por el incremento de las inversiones en infraestructura. Los programas masivos de empleo para la construcción de acueductos, alcantarillado, electrificación y vivienda tienen la virtud de mejorar las condiciones básicas de vida rural y de reducír los estímulos a la migración hacia las ciudades. Destaca en este sentido la capacidad de algunas actividades de carácter temporal -construcción de caminos vehiculares y de sistemas de riego- para generar también empleo permanente (Klein y Wurgaft, 1985). La construcción de microsistemas de riego local puede generar aumentos particularmente significativos en la producción y el empleo, en la medida en que la estrategia rural se centre en la materialización del potencial productivo latente del sector campesino.

En el mediano plazo, el mejoramiento del empleo rural no agrícola es imprescindible. Ya es indiscutible que este subsector crece más rápidamente que la ocupación agrícola: entre 1960 y 1980 aumentó del 12.5 al $21 \%$ de la población económicamente activa rural total en Brasil; del 19 al 36\% en Ecuador; y del 19 al $43 \%$ en Panamá (CEPAL, 1988, cuadro 29).

La construcción, la artesanía y el comercio son actividades ya tradicionales en casi cualquier cultura campesina, por lo que of recen de partida ventajas comparativas para la creación de empleo productivo rural. La artesanía y el comercio muestran fuerte presencia de mano de obra femenina, en tanto que la construcción ofrece un interesante potencial de expansión para absorber empleo masculino, en combinación con programas de autoconstrucción y de remuneración en alimentos. Este potencial puede orientarse al mejoramiento del parque actual de viviendas, en la medida en que se expanda la capacidad efectiva de demanda rural, pero puede alcanzar también a la infraestructura de carácter social: centros de salud, escuelas, salas comunales, locales comerciales, oficinas estatales, graneros y bodegas, etcétera.

La promoción del empleo no agrícola, desde una perspectiva de mediano plazo, exige, igualmente, complementar esta política con el ciclo anual de cultivos campesinos de granos básicos y otros. En general, las actividades no agrícolas que surgen en el campo tienen sus propios ciclos, como sucede con la agroindustria, la elaboración de insumos para la agricultura, la construcción. el turismo y algunos rubros comerciales y de manufacturas, pero muchos de éstos son complementarios de los del campesinado. El Estado puede promover la creación de estos empleos temporales, tanto mediante proyectos de infraestructura como el apoyo a microempresas cooperativas o comunales.

A más largo plazo, el empleo no agrícola rural adquiere una importancia crucial. La capacidad de absorción de mano de obra por parte de la agricultura es limitada, sobre todo si se pretende ir elevando la productividad y el ingreso de las personas ocupadas en este sector. Pasada una primera etapa en que se apoya a la economía campesina y se promueven medidas para la agricultura comercial que redundan en incremento de los requerimientos de mano de obra, es probable que la tasa de expansión del empleo agrícola vuelva a disminuir, sea cual fuere la estrategia que se adopte. Es previsible, asimismo, que en el largo plazo las nuevas ocupaciones no agrícolas demanden una mano de obra más calificada, sea en la agroindustria, por la ruralización de industrias de bienes duraderos o en los servicios sociales.

\section{El fomento de la demanda}

En numerosos programas de desarrollo de la agricultura campesina ha sido más fácil aumentar inicialmente la producción que manteneria en su nuevo nivel. A menudo los pequeños productores han pasado en breve plazo de la euforia a la decepción, al saturar una buena cosecha el mercado y hacer que los precios se derrumben, precipitando a la ruina a los campesinos que se habían endeudado para realizar inversiones. Un buen servicio público de acopio y regulación del mercado de granos y otros cultivos puede evitar catástrofes de este tipo en el corto plazo, pero será incapaz de impedir la sobreoferta crónica que derive de un "éxito desmesurado" en el fomento de la producción campesina.

Obviamente, los aumentos de la oferta deben ir acompañados de una baja de los costos de producción y de comercialización, así como, sobre todo, de un incremento del poder adquisitivo 
de los amplios estratos de consumidores que perciben bajos ingresos. En varios paises se promueve la construcción de silos y graneros familiares y comunales, a fin de asegurar el abastecimiento y la conservación de alimentos para los productores mismos. Igualmente, se apoya la entrega directa de hortalizas frescas a consumidores urbanos. Aunque se tiende a exagerar la magnitud de las ganancias y la ineficiencia de los pequeños y medianos intermediarios, no cabe duda de que la ayuda estatal en cuestiones logísticas, legales y de asesoría suele abaratar y agilizar los flujos de estos productos, en beneficio de productores y consumidores (Monge, 1987; Iturriaga, 1987; CIERA, 1987).

El mejoramiento del poder adquisitivo de la población urbana es un tema que excede el ámbito de este trabajo. Sin embargo, merece recordar que, a diferencia de lo que sucede con los hogares de estratos medios y altos, las familias urbanas más pobres aumentan en forma más que proporcional sus gastos en alimentos en la medida en que mejora su ingreso por persona.
Ahora bien, el éxito de las políticas de generación de empleo y de mejoramiento de los ingresos en favor de los estratos populares suscitaría, previsiblemente, cambios en la composición de la canasta familiar de alimentos. En la fase siguiente, entonces, sería indispensable que el sector campesino complementara el cultivo de granos básicos, diversificando cada vez más su oferta,de modo de cubrir también productos de actividades tales como ganadería intensiva, piscicultura y lácteos, frutas y verduras, etcétera.

Por último, como en muchos paises latinoamericanos la desnutrición se concentra en el ámbito rural y, más precisamente, en el campesinado minifundista, puede anticiparse que los incrementos de producción y ventas en los rubros a los que ellos se dedican de preferencia tendrán un impacto directo de considerable significación sobre la demanda de tales bienes, sea vía autoconsumo o mediante el intercambio horizontal entre zonas de especialización agrícola. A su turno, este fenómeno abrirá nuevos mercados a los bienes manufacturados de consumo masivo (BID, 1986).

\section{III}

\section{Reflexiones finales}

\section{Cambio social nural y desarrollo global a largo plazo}

Se vuelve así al tema inicial de este trabajo, vale decir, el imperativo de realizar el potencial de la oferta y de la demanda de los estratos pobres del medio rural para expandir el mercado interno, así como el papel que compete a la política social rural dentro de un desarrollo global sostenido, a la luz de las restricciones que enfrenta actualmente America Latina.

En el largo plazo, el tipo de estrategia que se ha propuesto aquí sólo tendrá éxito si consigue que el campesinado —en lugar de generar excedentes cada vez mayores de mano de obra, que presionan en el mercado de trabajo no calificado urbano- se convierte en generador de empleo productivo y dinamizador del mercado interno. Para tal efecto es imprescindible ofrecer mejores oportunidades ocupacionales y expectativas de vida a las nuevas generaciones de jóvenes campe. sinos, de modo de empezar a reducir la brecha de bienestar que separa las zonas rurales del mundo urbano. Es necesario, igualmente, que las familias campesinas puedan efectivamente mantener a sus hijos en estudios de tiempo completo hasta el nivel secundario, renunciando al uso de su fuerza de trabajo. Esto implica una inversión de largo plazo y un mejoramiento de la calidad de vida de cada hijo. La reducción de la diferencia de fecundidad entre éste y otros grupos sociales ${ }^{3}$ se verá acelerada también si se amplían las oportunidades educacionales, que favorecen la movilidad desde el campesinado hacia ocupaciones de alta calificación y productividad en otros sectores.

A corto o largo plazo, entonces, la creación de empleo rural tiene que ir mucho más allá del logro de la mera supervivencia, siendo impres-

\footnotetext{
${ }^{\mathrm{s}} \mathrm{La}$ tasa de fecundidad global de las mujeres en familias campesinas es alrededor del doble de la que se observa entre las de clase media (CEL.ADE, 1987).
} 
cindible que favorezca también la movilidad ocupacional ascendente en las propias zonas rurales, sea en la agricultura o en otras actividades.

Para la materialización de esta meta y la del retiro paulatino de los hijos desde las faenas de explotación del predio familiar se requiere que los estratos populares -campesinos o asalariados- acrecienten significativamente el control que ejercen sobre diversos recursos productivos. A su vez, ello exige superar el enfoque con que tradicionalmente se ha encarado el desarrollo rural. Supone, también, que los estratos populares de las áreas rurales asuman el papel que les compete en el quehacer democrático de la sociedad civil.

\section{La priesta en práctica de las buenas ideas}

Las secuelas de la crisis obligan a reorientar drásticamente las políticas socioeconómicas rurales. Para combatir la extrema pobreza y la inequidad rurales, se dispone desde ya de una extensa gama de buenas ideas, técnicas apropiadas y políticas eficaces. Es posible imaginar, asimismo, más de una línea estratégica viable para la década de 1990, mediante la combinación de diversas politicas como aquellas mencionadas.

La cuestión de éxito o fracaso pasa a depender entonces de como se financiarán estas reformas y cómo se logrará la fuerza política para llevarlas a cabo, dos interrogantes de indole netamente práctico. En las páginas precedentes se ha intentado enfrentar ambas preguntas, aunque necesariamente en forma abstracta y escueta. En cuanto al financiamiento, más allá de la atenuacion de las extremas desigualdades imperantes en el medio rural, se requiere transferir a éste recursos provenientes desde la sociedad urbana. Aqui se ha sostenido que tal proceso resultaria beneficioso para el país en su conjunto. En lo concerniente a la viabilidad política, hemos suge- rido que el punto de partida sería la operacionalización del principio abstracto de la participación popular.

Varios paises latinoamericanos han desplegado esfuerzos en el último tiempo para poner en práctica estrategias del tipo general como las propiciadas en este trabajo. La creciente inquietud ante la evolución que sigue la pobreza rural ha inspirado acciones concretas de intervención en diferentes contextos nacionales. En estos casos, se observa la presencia simultánea de tres elementos estratégicos: i) la asignación, garantizada por ley, de un porcentaje del presupuesto federal o de la recaudación del iva (impuesto al valor agregado) o de los aranceles sobre las importaciones, de modo de proveer financiamiento masivo y permanente a las zonas de mayor pobreza; ii) la modernización de los gobiernos municipales, los cuales se transforman en ejecutores descentralizados de la planificación del desarrollo; y iii) la creación de consejos de elección popular, a nivel local, municipal y provincial, dotados de poderes decisorios para la selección y administración de proyectos locales de desarrollo (Bustamante, 1987; República de Colombia, 1987; República de Guatemala, 1987).

El futuro próximo será la prueba de fuego de estas estrategias. El gran interrogante es si las alianzas y movilizaciones tendrán la suficiente fuerza para llevar las disposiciones legales a la práctica, frente a la tenaz resistencia y contraofensiva de los intereses creados y los circuitos de poder locales y regionales. Si tales estrategias fracasan en el empeño, las medidas de financiamiento y movilización participativa, concebidas precisamente para materializar las buenas ideas disponibles para el desarrollo social rural, serán recordadas, también, como otras de las tantas buenas ideas que se estrellaron contra las inamovibles estructuras del privilegio.

\section{Bibliografia}

Altieri, M. (1987): Bases ecologicas para el desarrollo de sistemas agricolas allernativos para campesinos de Latinoamérica. Reunion cEPAL-Fao sobre Estrategias de Desarrollo Agrorrural con Participación Campesina, Santiago de Chile, noviembre.

Barril, A. (1987): Cooperativas y arganizacion campesina: eshadio de las tiendas campesinas en la VI Region de Nicaragtaa, Managua.

BID (1986): Progreso economico y social en America Latina. Banco Interamericano de Desarrollo.

Bustamante, S. (1987): Las gobiemos locades y el desarrollo mural: notas sobre el caso colombiano. Reunion CEPAL-FAO sobre 
Estrategias de Desarrollo Agrotrural con Participación Campesina, Santiago de Chile, noviembre. CELADE (1987): Boletín demografico, $\mathrm{N}^{\circ} 39$, enero. CEPAL (1985): La pobreza en América Latina: dimensiones y políticas. Estudios e informes de la CEPAL, N" 54.

(1986 a): Transición estrutural, movitidad ocupacional y crisis social en America Latina, 1960-1983 (LC/R. 547).

_. (1986 b): Balance preliminar de la economía latinoamericana.

(1987 a): La crisis del desarrollo social: retas y pasibilidades (LCL. 413).

(1987 b): Anuario estadistico.

(1988): Restricciones al desarvollo sostesido en América Latina y el Caribe y requisitos para su superación (LC/G. 1488 (sEs 22/3)/Rev, 1), 8 febrero.

CFPAL-FAO (1985): Agricultura campesina en América Latina y el Caribe.

(1987): Crists, proceso de ajuste y efectos sobre la agricultura en America Latina.

CIERA (1987); Abastecimiento campesino, 1987-1988, Managua.

Commander, C. y P. Peek (1983): Oil exports, agrarian change and the rucral labour process, OIT, WBP 10-6/WP 63, Ginebra.

Dunham, D. (1983): Historia y economía política de las políticas relacionadas a los pequet̂os agricultores. Revisia de la CEPAL, $\mathrm{N}^{\circ} 18$.

Durston, J. (1982); Clase y cuitura en la transformación del campesinado. Revisto de la CEPAL, $\mathrm{N}^{\circ} 16$.

(1983 a): El sistema alimentario mexicano: fun nuevo estito de desarrollo social rural? CEPAL (E/CEPAL/SEM/R. 13).

( 1983 b): Comunidad andina, gestión de recursos y diferenciación social. Sobrevivencia campesina en ecosistemas de allura, CEPAL-PNUMA, vol. 1, Santiago de Chile.

y A. Crivelli (1984): Diferenciación campesina en la sierra ecuatoriana. Estrategias de supervivencia en la comunidad ardina. M. Chiriboga at al., (:AAP, Quito.

Estévez, G. (1980): Qué hay detrás de la crisis rural. Comercio Exterior, julio.

Hewitt, C. (1976): Modernizing Mexican agrtculdure, UNRISO, Ginebra.

Iturriaga, J. (1987): Programas sociales masivas de conasupo. Coloquio Internacional sobre Comercio en Programas Sociales Masivos. Centro Latinoamericano para la Administración del Desarrollo, Buenos Aires.

Klein, E. y J. Wurgaft (1985): La creacion del empleo en pertodos de crisis, PREALC.
Lacroix, R. (1985): Integrated rural development in Latin America. World Bank Working Paper 716, Washington D.C.

Longhurst, R, (1987): Policy approaches toward small farmers. Adjustement with a human face: protecting the vulnerable and promating growth, G. Cornea y otros., uNicEs.

Llambi, L. (1979): El mercado de trabajo en la agricultura empresarial venezolana. Estudios rurales latinoamericanos, Vol. $2, \mathrm{~N}^{\circ} 3$.

Monge, C. (1987): Las ferias del agrictulor en Costa Rica. Reunión CePal-Fao sobre Estrategias de Desarrollo Agrorural con Participación Campesina, Santiago de Chile, noviembre.

Palau, T. (1987): Redestinacion de los subsidias estatales hacia el sector campesino. Reunión CEPAL-FAo sobre Estrategias de Desarrollo Agrorrural con Participación Campesina, Santiago de Chile, noviembre.

PREALC (1986): La creación del empleo productivo: una tarea impostergable.

República de Colombia (1987): Fundamentos del Plan Nacional de Rekabilitación. Presidencia de la República.

República de Guatemala (1987): Decreto Loy 52-87 de los Comsejos de Desartollo Rural y Urbono. Congreso Nacional.

República de Nicaragua (1986): Evaluación de siete años de la reforma agraria y el desarrollo agropecuario. Ministerio de Desarrollo Agropecuario y Reforma Agraria.

Revista Coyuntura Agropecuaria (1987): Reforma agraria: ele* mentos para el debate. Suplemento especial $\mathrm{N}^{\mathrm{o}} 1, \mathrm{Co}_{0}$ lombia.

Schejtman, A. (1987 a): Campesinado y seguridad alimentaria Estudios rurales latinoamericanos, vol. 10, $\mathrm{N}^{3} 3$.

- (1987 b): Biotecnologia y campesinado: notas para una reflextón. Reunión CEPAL-FAo sobre Estrategias de Desa. rollo Agrorrural con Participación Campesina, Santiago de Chile, noviembre.

Thiesenhusen, W. (1987): Rural development questions in Latin America. Latin American Research Review, xxul.

Warman, A. (1977): La colectivización en el campo: una critica. Cuadernos politicos, México.

Wilk, R. (1987): The search for tradition in southern Belize. America indígena, vol. XLVII, $\mathrm{N}^{\circ} 1$.

Wulf, E. (1986): Beyond the Green Revolution: new approaches for Third World agriculture. Worldwatch $P$ apers 73 , Washington D.C. 